\title{
La policía en La Habana durante el siglo XIX
}

\author{
DOI: 10.15175/1984-2503-20179302
}

\section{Yolanda Díaz Martínez ${ }^{1}$}

\begin{abstract}
Resumen
Durante el siglo XIX la policía asumió disímiles funciones que fueron variando desde las clásicas y propias de una policía urbana hasta la asunción de obligaciones atribuibles a una policía judicial. De tal forma lo mismo podía encargarse de organizar la vida social y las diferentes actividades cotidianas en la ciudad, hasta la labor de vigilar, controlar y reprimir el delito, en función de lo cual fueron dictadas a lo largo del XIX diversas disposiciones encaminadas a regular su funcionamiento y alcanzar mejoras en su organización. No obstante, resultaron frecuentes a lo largo de ese siglo numerosas quejas que ponían en tela de juicio el adecuado y eficiente funcionamiento del cuerpo judicial, varias causas generaron esas dificultades algunas relacionadas con la heterogeneidad del personal seleccionado para integrarla o la falta de moralidad de algunos de sus integrantes y en otros casos con la ineficiente infraestructura existente en la ciudad que impedía pudiera funcionar con efectividad.
\end{abstract}

Palabras claves: policía; delito, justicia; delincuente.

\section{A polícia de Havana durante o século XIX}

\section{Resumo}

Durante o século XIX, a polícia assumiu diferentes funções, desde a clássico e típica intervenção de uma polícia urbana até assumir obrigações atribuíveis a uma polícia judiciária. Assim sendo, poderia caber-lhe organizar a vida social e as diferentes atividades cotidianas na cidade ou ainda a tarefa de vigiar, controlar e reprimir os crimes, atribuições estas que, no transcorrer do século XIX, suscitaram várias disposições visando regularizar o seu funcionamento e alcançar melhorias em sua organização. No entanto, ao longo do século ocorreram inúmeras queixas, questionando a adequação e a eficiência do órgão judicial. Várias causas originaram essas dificuldades, algumas relacionadas à heterogeneidade do pessoal selecionado ou a desvios morais de alguns dos seus integrantes e, em outros casos, ligadas à ineficiente infraestrutura existente na cidade, impedindo que o referido órgão pudesse funcionar eficazmente.

Palavras-chave: Polícia; crime; justiça; delinquente.

\section{Police in Havana in the Nineteenth Century}

\section{Abstract}

Throughout the nineteenth century, the police performed various roles ranging from those traditionally and properly associated with urban police to the assumption of obligations in line with judicial police. In this context, the force also came to be responsible for organizing the city's social life and a variety of everyday activities, including the surveillance, control, and suppression of crime, leading to the introduction of various initiatives throughout the nineteenth century to regulate operations and improve organization. Despite this, countless complaints were made throughout the century challenging the appropriateness and efficiency of the judicial body. Various factors were behind such difficulties, with some related to the heterogeneity of the personnel selected or the lack of morality displayed by officers, and others stemming from the city's lack of effective infrastructure, preventing the police from operating effectively.

Keywords: Police; crime, justice; criminal.

\footnotetext{
${ }^{1}$ Investigadora Titular y Directora de Investigaciones del Archivo Nacional de la República de Cuba. E-mail: ydiazmartinez66@gmail.com
} 


\section{La police à La Havane au XIXe siècle \\ Résumé}

Au long du XIXe siècle, la police a assumé différentes fonctions qui ont pu varier des attributions habituelles propres à une police urbaine à celles d'une police judiciaire. Ainsi, un même service pouvait être chargé d'organiser la vie sociale et les différentes activités quotidiennes de la ville, mais également de surveiller, contrôler et réprimer les délits, raison pour laquelle diverses mesures furent adoptées au cours du XIXe siècle pour réguler le fonctionnement et améliorer l'organisation de l'institution. Ce même siècle verra néanmoins se succéder d'innombrables plaintes remettant en question le fonctionnement du corps judiciaire. Diverses causes sont à l'origine de ces difficultés, dont certaines liées à l'hétérogénéité du personnel recruté ou à la moralité défaillante de certains des membres de la police, voire à la faiblesse des infrastructures urbaines qui l'empêchait de se déployer efficacement.

Mots-clés : Police ; délit ; justice ; délinquance.

\section{9 世纪古巴哈瓦那警察局}

摘要

在十九世纪期间，古巴的哈瓦那警察承担了不同的职能，从典型的城市治安警察到履行责任的司法警察。同样 地，他们可以在城里组织社会生活和日常活动，监督，控制和制止犯罪。因此，在整个十九世纪里，政府多次 出台法令，旨在规范警察制度的运作并且改善警察组织。然而，在整个十九世纪，对司法制度的投诉非常频繁 ，投诉的内容包括：司法机构能否充分和有效运作的问题；司法从业人员质量参差不齐的问题，甚至有的人道 德素质低下; 由于城市的低效基础设施，使得司法人员无法有效地工作等等。

关键词: 警察; 违法; 犯罪; 司法

Las funciones y el papel asumido por el cuerpo de policía en diferentes contextos y épocas, así como los diversos procesos de reformas por los que ha atravesado hasta llegar a sus características actuales, han generado numerosos estudios que mantienen criterios diversos y, a veces encontrados, cuando se intenta definir a qué se alude al hablar de Policía.

Aunque el vocablo encuentra su definición en la Real Academia de la Lengua como un cuerpo encargado de velar por el mantenimiento del orden y la seguridad de los ciudadanos, sujeto a la órdenes de las superiores autoridades políticas, en cuanto a términos académicos su significado no resulta tan sencillo, ni tampoco hay una paridad de puntos de vista en cuanto a qué representa: "[...] para unos son los guardianes de la ley convertidos en los enemigos del pueblo, para otros el último bastión de la sociedad asediada. La policía -lo sabemos- siempre ha sido y seguramente será una institución polémica, de consideración imprecisa", ${ }^{2}$ más aun en el contexto actual latinoamericano, donde su actuación en algunos países del área es sumamente cuestionada.

2 GALEANO, Diego; KAMINSKY, Gregorio (Org.). Mirada (de) uniforme: historia y crítica de la razón policial. Buenos Aires: Teseo, 2011, p. 9. La literatura sobre el tema resulta numerosa, destacándose en el debate en torno a esta cuestión especialistas de países como Argentina, México, Chile y Brasil; además de los tra- 
En el ámbito Hispanoamericano el origen de la policía se asocia a los finales del siglo XVIII, en el marco de la reforma liberal de la administración local que se afianza en España y la reformulación del concepto de Estado, de manera más particular a la forma en que este ejerce su poder; como resultado aparecen los tratados policiales que aluden a una nueva forma del control social, en las que organización, administración, orden, etc., se convierten en cuestiones esenciales de su acción.

Bajo ese concepto, la policía también llegó a las colonias españolas de Ultramar, como parte de la centralización de los sistemas de control y represión de conductas contraventoras y de los cambios en las relaciones sociales provocados por la modernidad que trajo aparejada las ideas ilustradas, un buen ejemplo de ello lo encontramos, de manera particular, en ciudades como Quito, Buenos Aires o a un nivel más genérico en países como Perú, Chile, México y Venezuela. ${ }^{3} \mathrm{~A}$ partir de las reformas borbónicas el pensamiento ilustrado comienza a introducir políticas que se refieren a la vida urbana y multiplican las disposiciones policiales sobre las conductas en la ciudad, en el marco urbano en casi todos estos sitios coincide con una constante en sus funciones: administración, orden, limpieza, etc., en fin, el buen gobierno de las ciudades.

Cuba no fue una excepción en este proceso. Inexplicablemente para el caso cubano se aprecia un vacio historiográfico, a la vez que resulta notable la ausencia de debates en torno al origen, funciones, evolución y cambios que se experimentan en la policía desde su aparición hasta fechas más contemporáneas. Abocado el quehacer investigativo hacia otros tópicos privilegiados por las políticas editoriales y las discusiones académicas, la bibliografía sobre el tema, además de resultar sumamente escasa y en muchos casos desactualizada, ${ }^{4}$ se dirige fundamentalmente a detallar su actividad, sin hacer énfasis en

bajos incluidos en el citado texto, ver también como estudios de caso HOLLOWAY, Thomas $\mathrm{H}$. Policing Rio de Janeiro: repression and resistance in 19th-century city. California: Stanford University Press, 1993. Así como diversos artículos compilados en otras ediciones colectivas, entre ellas GAYOL, Sandra; KESSLER, Gabriel (Org.). Violencia, delitos y justicia en Argentina. Buenos Aires: Manantial SRL, 2002; más recientemente PALMA ALVARADO, Daniel (Org.). Delincuentes, policías y justicia: América Latina, siglos XIX-XX. Santiago: Ediciones Universidad Alberto Hurtado, 2016.

${ }^{3}$ KINGMAN GARCÉS, Eduardo; GOETSCHEL, Ana Maria. Seguridad y policía en la ciudad de Quito en el siglo XIX e inicios del XX. Revista Latinoamericana de Seguridad Ciudadana, Quito, n. 7, p. 74-82, mayo 2009. Cross Ref.; VACCARONI, Agustina. La Intendencia de Policía de Buenos Aires: de las reformas a la Revolución, Gobierno, Higiene urbana y Control Político, Revista de la Red Intercátedras de Historia de América Latina Contemporánea, Córdoba, año 2, n. 3, p. 8-23, dic. 2015. Disponible en: <https://revistas.unc.edu.ar/index.php/RIHALC/article/view/13419/17255>. Acceso en: 22 abr. 2017.

${ }^{4}$ Sobre la actividad y funcionamiento de la policía: TRUJILLO Y MONAGAS, José. Los criminales de Cuba: narración de los servicios prestados en el Cuerpo de Policía de La Habana. Barcelona: Establecimiento Tipográfico de Fidel Giró, 1882; VARELA ZEQUEIRA, Eduardo. La policía de La Habana. La Habana: Imprenta La Universal, 1894; ROCHE MONTEAGUDO, Rafael. La Policía y sus secretos en Cuba. La Habana: Imprenta La Moderna Poesía, 1925. 
cuestiones vitales como modelos, estructura, funcionamiento, etc.; una situación que se complejiza para la etapa actual, en la que los estudios vinculados al ámbito policial se gestan hacia el interior de dicho cuerpo realizado por especialistas vinculados de alguna forma al mismo, por lo que no hay una socialización de los resultados que propicie su conocimiento y enriquecimiento.

Teniendo en cuenta esos precedentes este primer estudio, se encamina a analizar el funcionamiento de la policía en Cuba durante el siglo XIX, haciendo énfasis de manera particular en La Habana, donde, de manera similar a lo acontecido en las restantes colonias de España en América, la policía asumió la función de garantizar el cumplimiento de lo pautado desde el poder. Como parte del reordenamiento de la sociedad, se aplicaron nuevas estructuras que reglamentaron los comportamientos sociales a partir de normas y disposiciones de estricto cumplimiento, entre ellos la puesta en práctica de bandos de buen gobierno encaminados a "ordenar"-apelando al criterio ilustrado-, las prácticas de convivencia y las actividades cotidianas de los habitantes. ${ }^{5}$

\section{Los orígenes de la policía}

En Cuba, las primeras disposiciones estableciendo atribuciones para la policía se remontan al gobierno de Felipe de Fondesviela y Ondeano, Marqués de la Torre (17711777), aunque sus funciones todavía no quedaban adecuadamente delineadas y se correspondían, más que todo, con un reordenamiento de la sociedad en el marco de un nuevo orden económico y moral, resultado de la impronta de la ilustración en las colonias hispanas. ${ }^{6}$ Por tal razón, aun aparecen sin suficiente definición los límites de lo permitido/no permitido o los mecanismos para garantizar el deslinde de ese binomio, todo ello unido con la organización de la ciudad y evitar el desorden en las calles.

El Reglamento de policía aprobado en 1820 ya tendría otra connotación, el articulado que lo componía se encaminó a perfilar con una mayor objetividad las funciones del

${ }^{5}$ GALEANO, Diego. En nombre de la seguridad: lecturas sobre política y formación estatal. Cuestiones de Sociología, Buenos Aires, n. 4, p. 102-125, 2007. Disponible en: <http://www.cuestionessociologia.fahce.un|p.edu.ar/article/view/CSn04a05>. Acceso en: 4 abr. 2017.

${ }^{6}$ Similar a lo que ocurre en otros contextos latinoamericanos, durante ese último cuarto del siglo XVIII la acción policial también se dirige a enfrentar nuevas figuras que aparecen en el escenario social, definidos indistintamente en el discurso oficial como vagos y "mal entretenidos". No es casual que pocos años después bajo el gobierno de Luis de las Casas (1790-1796) aparezcan las primeras reglamentaciones para controlar la vagancia. 
cuerpo. ${ }^{7}$ Aunque el texto no aclara su alcance, nacional o local para La Habana, su contenido muestra que estamos frente a un reglamento que aboga por un modelo de policía municipal, vinculado a los problemas que acontecen en ese estrecho marco y donde la administración colonial, sin renunciar a su papel de controlador en tal cuestión, confiere una especial relevancia al municipio y las estructuras creadas para su funcionamiento, similar a como funcionaba en España y gran parte de Europa en general. ${ }^{8}$ Esa relación entre gobierno general/gobierno municipal respecto a la administración policial, atravesaría por diferentes momentos a lo largo del siglo XIX.

Los artículos del reglamento reflejaban algunos de los principales problemas que enfrentaba la ciudad: deficiente alumbrado, los obstáculos que ocasionaban las diferencias constructivas y de trazado entre los barrios que la componían, así como la falta de control de la población que se movía a través de sus diferentes espacios, en función de esto se estructuró el sistema de vigilancia, donde aparece como una novedad para Cuba el establecimiento de cuarteles en cada uno de los barrios, demarcados en intramuros y extramuros. $^{9}$

La ubicación de esos enclaves debía permitir una mejor vigilancia de los habitantes y de la situación de la urbe en general; aunque el interés se centraba inicialmente en el centro urbano, donde se concentraba el mayor número de habitantes y se desarrollaba la actividad comercial, ese control se extendió a las zonas exteriores, reforzando la actividad de vigilancia con las milicias como órgano auxiliar. En los sectores de extramuros, apartados del centro, con insuficiente iluminación y una extensa área a patrullar -en ocasiones con amplios espacios despoblados-, se estableció más de un cuartel por barrio, en enero de 1823 en Guadalupe había 7, en el barrio de Jesús María 5 y en San Lázaro 3.

El conocimiento de quienes habitaban la ciudad y la actividad a la que se dedicaban constituyó una prioridad insuficientemente cubierta con los padrones vecinales con-

\footnotetext{
${ }^{7}$ REGLAMENTO de policía. In: Colección Facticia de Vidal Morales. La Habana: Compilado por la Biblioteca Nacional de Cuba José Martí. T. 57. p. 20-25, 1820. Disponible en: <http://www.bnjm.sld.cu/cgibin/search.py?cadbusca="Col.+facticia"+"reglamento+de+policía"\&idficha=bnjmsculyfof0010001\&idcatalogo $=\& a p i$ key=\&start=0\&rows $=10 \& \mathrm{i}=1 \& \mathrm{j}=1 \&$ sort=id+asc $>$. Acceso en: 12 abr. 2017. Este reglamento coincide con el auge del proceso independentista de las colonias hispanas en América y la situación de crisis que crea en la metrópoli el Trienio liberal, con fuerte influencia en algunas de las estructuras establecidas en la colonia cubana, intentando elevar el control sobre la población a fin de evitar cualquier hecho que pudiera poner en riesgo la estabilidad política.

${ }^{8}$ EMSLEY, Clive. Los modelos de policía en el siglo XIX. In: GALEANO, Diego; KAMINSKY, Gregorio (Org.). Mirada (de) uniforme: historia y crítica de la razón policial. Buenos Aires: Teseo, 2011. p. 21-46.

${ }_{9}$ Los barrios de intramuros eran 16: San Telmo, Fuerza, Gobierno, Santo Domingo, San Francisco, Santa Clara, Espíritu Santo, Paula, San Isidro, Belén, Santa Teresa, Ursulinas, Monserrate, San Felipe, Ángel, San Juan de Dios, en tantos los existentes más allá de la Muralla eran: San Lázaro, Colon, Peñalver, Guadalupe, Jesús María y Chávez.
} 
feccionados por los alcaldes de barrios, esto abrió la posibilidad para que desde fechas muy tempranas la policía también asumiera una función reguladora del movimiento dentro de la ciudad, ejercido a través de cédulas o papeletas de identificación que debían portar las personas en su diario movimiento por la ciudad, así como la concesión de permisos a quienes llegaban a la isla.

Otros dos ejes marcaron el funcionamiento de la policía: el orden y la higiene. En cuanto al primero entraba en sus facultades intervenir en cualquier disturbio que alterase la tranquilidad y la represión de cualquier acción o comportamiento conceptuados según los criterios predominantes en la época como una agresión a la moral y las "buenas costumbres", por supuesto dictadas o establecidas desde el poder. Así mismo quedaban encargados de perseguir delincuentes, casi siempre acompañados de militares; también participaban en el cierre de los establecimientos que permanecieran abiertos después de las 10 de la noche - hora fijada para su cierre-, así como las casas y otros sitios donde se jugaba sin estar autorizados.

En el ámbito de la higiene mantenía algunas de las funciones asumidas desde su creación e incorporaba otras nuevas, resumidas en cuestiones tan diversas como la distribución del espacio público a partir de vigilar el emplazamiento e inspección de los mercados, mataderos y cualquier otra industria o establecimiento que pudiera comprometer la salubridad; de forma paralela velaban por el trazado de calles, el ornato, la recogida de basuras, así como por el cumplimiento de lo dispuesto respecto a la ocupación de los diferentes espacios por cada grupo poblacional, acorde a los cánones establecidos para una sociedad marcada por preceptos raciales y estamentales, en la que la posición social, el color de la piel o la condición de negro libre o esclavo marcaba una diferencia.

Esta diversidad de funciones, entre las cuales la persecución de delincuentes solo era una más -ejecutada por demás con el apoyo de las milicias-, nos muestra a la policía como un cuerpo, que más que encargarse de luchar contra la criminalidad, era concebido como entidad encaminada al sostenimiento del orden en un sentido más amplio, intentando mantener un equilibrio en las relaciones que se establecían entre los diversos actores sociales, en ocasiones bajo condiciones más complejas generadas por algunos movimientos poblacionales del campo hacia la ciudad o de otras regiones hacia La Habana por causas económicas. ${ }^{10}$ 10 Habría que realizar estudios más profundos para establecer el modelo aplicado de policía aplicado en
Cuba y su pertinencia con algunos de los reconocidos hasta ahora: la tradición francesa, la anglo-
norteamérica o la alemana. En todo caso hay algunos atisbos que pudieran relacionarla con la segunda de 
El reglamento de policía aprobado en 1820, concedía un importante rol al Regidor o Síndico inspector de Policía, con amplitud de funciones: conciliar las desavenencias entre vecinos, impedir cualquier desorden que turbara la tranquilidad pública como robos, heridas $u$ otros de igual urgencia; una importante atribución concedida a él era el cobro de las multas según lo prescrito en las leyes, reportando a los alcaldes cualquier incidencia en el cumplimiento de dicha actividad. ${ }^{11}$

El funcionamiento de la policía mostró, casi desde los mismos inicios, fisuras que incidieron en los problemas de competencia que presentó el cuerpo, ocasionados, en principio, por la heterogeneidad de sus integrantes, elegidos de los respectivos vecindarios en calidad de voluntarios, por tanto no era un cuerpo profesional, sus integrantes no provenían del ejército y tampoco percibían un jornal por su actividad de vigilancia al carecer de un fondo que permitiera a los integrantes disponer de un salario fijo.

Resulta notorio el hecho de que a pesar de no recibir estas plazas una remuneración, resultasen muy codiciadas y disputadas, lo que se explica por las atribuciones concedidas a los diputados y vigilantes de policía en el cobro de multas bajo condiciones muy favorecedoras, tal y como lo refleja el siguiente fragmento del reglamento vigente:

[...] para estimular á estos al más eficaz cumplimiento de sus obligaciones, e indemnizarlos en parte de su trabajo, se les consigna la mitad de las multas que exigiere, que han de ser con orden por escrito del Diputado, reservándose este la otra mitad de las multas a favor de los gastos de policía [...].12

De esa forma quedaba un espacio abierto al fraude y el engaño en beneficio de agentes y funcionarios. Cada tres meses los diputados debían ingresar en la caja de gastos de la ciudad el dinero de las multas cobradas que no hubiese sido desembolsado en necesidades del órgano, junto a un documento que recogía las multas cobradas y el porciento deducido por gastos de policía; ese mecanismo, sin otra forma de control, posibilitaba alterar las listas de relación de multas, declarar menos de lo que realmente se cobraba por cada una de ellas o elevar la cifra de gastos al no fijar una cantidad constante 0 proporcional en este acápite.

A lo anterior hay que añadir la selección, frecuentemente arbitraria, de los designados para ocupar cargos dentro del cuerpo. El número de criollos aceptados siempre era

esas propuestas, más aun si tenemos en cuenta que la emisión de reglamentos policiales o modificaciones a los existentes coinciden con movimientos de población como los acaecidos en las décadas de 1820 y 1830 ante el avance del azúcar y la reestructuración en el uso de la tierra, o en la década de 1860 con un proceso de guerra en la zona centro oriental de la isla que ocasionó un traslado de parte de la población hacia La Habana en busca de mejores opciones y condiciones de vida. GALEANO, 2007.

${ }^{11}$ REGLAMENTO de Policía, 1820, T. 57. p. 20-25.

12 Ibidem. 
minoritario y se sustentaba en juicios subjetivos al hacer recaer en criterios de arraigo, honradez y fidelidad a la corona los principales atributos que debían demostrar los seleccionados, mientras capacidad y aptitud quedaban relegadas a un segundo plano, por lo que era frecuente que no siempre los aceptados resultasen idóneos o eficientes. Similar a lo que acontecía en otros ramos de la administración, la mayor parte de los funcionarios eran españoles, frecuentemente acusados de ser más indolentes con sus coterráneos y más exigentes con los criollos. Sebastián Kindelán (1822-1823), al abandonar el mando de la Isla, sugería a su sucesor Francisco Dionisio Vives (1823-1832) la necesidad de buscar un equilibrio de españoles y naturales del país para ocupar estos cargos "[...] ante el riesgo de que las preferencias mostradas lejos de coadyuvar al conveniente cuidado de la tranquilidad de la ciudad, condujese a conductas reprobables". ${ }^{13}$

Las acciones para hacer más eficiente el funcionamiento del cuerpo policial, no cesaron y en 1823 se emitió un nuevo Reglamento de Policía ${ }^{14}$ que conservó mucho del anterior y se apoyaba en las regulaciones establecidas en los Bandos de Buen Gobierno. Se mantuvo la misma división en cuarteles, a la vez que permanecían los diputados ahora bajo la denominación oficial de Comisarios-, con la función principal de mantener el orden y perseguir el juego y la vagancia. En el reglamento se incorporaba un nuevo funcionario: el Inspector de Policía, elegido uno por cada 3 ó 4 barrios, su función era actuar como intermediario entre los comisarios de cuartel o diputados y el alcalde. Cada comisario debía informar dos veces a la semana al Inspector de lo acontecido diariamente, quien lo transmitía a los alcaldes.

Con la incorporación del Inspector, lejos de lograr una mayor eficiencia respecto al funcionamiento del cuerpo policial, lo que se consiguió fue complejizar la estructura piramidal al alejar, aun más, a los funcionarios policiales de las autoridades administrativas más inmediatas, por ejemplo el alcalde, quien además gozaba de total autoridad para tomar decisiones en el ramo de policía. Con el nombramiento del nuevo funcionario la autoridad municipal entendió que la administración colonial intentaba restarle autoridad y capacidad de actuación al privarle del conocimiento directo de los sucesos que acontecían en la ciudad; por tal razón el ayuntamiento comenzó a cuestionarse la permanencia del cargo de inspector "cuya actuación puede ser discutible, toda vez que no siempre refleja

\footnotetext{
13 "Mejoras a tener en cuenta para una mejor administración de la isla". 21 de marzo de 1823. Archivo Nacional de Cuba (en lo adelante ANC), Fondo Asuntos Políticos (en lo adelante AP), Leg. 16, Exp. 50.

14 "Reglamento de Policía". 3 de agosto de 1823. ANC, Fondo Gobierno Superior Civil (en lo adelante GSC), Leg. 885, Exp. 29816.
} 
la realidad de lo que acontece en la ciudad, por lo que bien pudiera disponerse no ser necesaria su existencia"15 A pesar de las quejas y reclamos el gobierno colonial mantuvo al Inspector, quien ganaría en facultades hasta quedar como la persona que, de manera directa, rendía cuentas al gobernador general de la situación en el ramo de policía.

La persistencia de las dificultades e irregularidades ya mencionadas en cuanto a la selección del personal de policía, contribuyeron a sentar las bases que definirían su desempeño y el de los empleados afines a esta: corrupción, incapacidad y abuso de atribuciones.

\section{La policía y sus vicios}

Otros aspectos también contribuyeron a elevar los cuestionamientos respecto al funcionamiento del cuerpo policial, que no estuvo ajeno a muchos de los problemas que aquejaban a la sociedad habanera del XIX, en la que la corrupción, el juego y otros "males sociales", marcaban la cotidianidad. De manera particular. el cobro de las multas por los funcionarios de los diferentes cuarteles de barrio fue motivo de numerosas quejas y reclamaciones acusando a vigilantes y diputados de cobrar multas excesivas o injustificadas.

A modo de ejemplo, el 14 de octubre de 1823 algunos propietarios de alambiques denunciaban la actitud de los agentes policiales atribuyéndoles exceso de atribuciones y práctica de chantaje ${ }^{16}$ reclamaban que los diputados les impusieron multas superiores a los 100 pesos bajo amenaza de destruirles el negocio si no las pagaban inmediatamente o el pago de algún dinero para lograr una prórroga, si bien la autoridad municipal ya había dispuesto el traslado de esos sitios para las afueras de la ciudad al considerar que en la zona donde estaban ubicados podían ocasionar un incendio, se les había concedido de plazo hasta los día finales de ese propio mes.

De otros negocios también llegaban reclamos: varios matadores de reses en el rastro se quejaban de que les exigían dinero bajo el pretexto de que sacrificaban animales que no estaban en óptimas condiciones; a vendedores ambulantes por estar ubicados, supuestamente, en sitios que no les correspondían; así como a cereros y fabricantes de velas porque sus locales no reunían las condiciones de seguridad exigidas, etc.

\footnotetext{
${ }^{15}$ Acta de las sesiones del Ayuntamiento de La Habana correspondiente al 23 de febrero de 1824. Archivo
} de la Oficina del Historiador de La Habana (en lo adelante AOHH). Tomo 104. 
La frecuencia de las quejas ocasionó que el tema fuera llevado a las sesiones del Ayuntamiento de La Habana, sin conseguir poner coto a esos procederes pues los funcionarios superiores a los cuestionados no cumplían con sus obligaciones, algo que resultó habitual durante el gobierno de Vives y que tuvo su origen, entre otras causas, por la excesiva cantidad de funcionarios intermedios establecidos por la administración colonial que, lejos de hacer más efectivo el sistema de vigilancia, contribuyó a su lentitud e ineficacia.

Las dificultades antes expresadas respecto al desempeño de la policía, eran consideradas por los integrantes del Ayuntamiento de La Habana como una de las causas del progresivo aumento de los hechos delictivos que acaecían en la ciudad, así lo expresaba en sesión celebrada el 8 de junio de 1831 el Síndico Andrés Zayas:

[...] la infracción u olvido de nuestras leyes y los reglamentos de policía, y á la corrupción general que se nota en todas las clases por la inercia de los subalternos del gobierno, siendo mi opinión que todo mudaría en el instante que se variase el sistema de diputados por barrio y capitanes de partido y se ataque el ocio y la vagancia, que son las principales causas de los riesgos que nos amenazan. ${ }^{17}$

Y nuevamente se reflejaba la disputa entre el ayuntamiento local y el gobierno general al proponer la desaparición de los comisarios de barrio y solicitar que sus funciones fueran asumidas por los alcaldes, quienes tenían entre sus atribuciones las de una policía gubernativa que, con un buen desempeño, podía contribuir al restablecimiento de la tranquilidad. Sin embargo, la existencia de esos problemas desde mucho antes, con los consiguientes pronunciamientos realizados en las reuniones del Ayuntamiento, ponen de manifiesto que la solución no estaba en eliminar funcionarios o redistribuir funciones sino en la falta de cumplimiento de las obligaciones inherentes a cada cargo.

Ya en 1829 el Sindico Procurador José María Calvo y O'Farril expresaba en un informe $^{18}$ el olvido o incumplimiento de las funciones concernientes a los comisaros o diputados de policía y a los inspectores. Valoraba el procurador que los primeros, por abandono o por no afectar sus intereses, no querían comprometerse con los "poderosos" ni con los "ricos" temerosos de perder las ventajas de todo tipo que estos podían proporcionarle y, contradictoriamente, muchas veces en ese estamento poblacional radicaban problemas como el juego y el ocio.

\footnotetext{
${ }^{16}$ Acta de las sesiones del Ayuntamiento de La Habana correspondiente al 14 de octubre de 1823 . AOHH, Tomo 103.

${ }_{17}$ Actas del Ayuntamiento de La Habana. 8 de junio de 1831. AOHH, Tomo 117.

${ }^{18}$ Actas del Ayuntamiento de La Habana 9 de abril de 1829. AOHH, Tomo 114.
} 
En cuanto a los inspectores consideraba no mostraban celo en el cumplimiento de sus obligaciones: no tenían un estricto control del desempeño de los comisarios, no eran capaces de ejercer una vigilancia efectiva desde sus respectivos cuarteles y tampoco exigían a otros funcionarios subalternos el puntual desempeño de sus obligaciones, razones que justificaban una mayor exigencia y su destitución, concluía el síndico: "Cuando hay vigilancia, cuando hay empeño de cada uno en llenar su deber es muy difícil se cometan delitos y si tal sucede son descubiertos al momento y sus autores castigados"19

Dentro de las amplias atribuciones conferidas en la isla al Ayuntamiento estaba la potestad de implementar medidas para resolver los problemas que enfrentaba la ciudad, mediadas, solo, con la aprobación del Gobernador de la isla; esa capacidad, sin embargo, frecuentemente se veía retardada a causa de los procedimientos establecidos que solo contribuían solo contribuían a dilatar la solución de los problemas. ${ }^{20}$

\section{En busca de una policía más eficiente}

La falta de confianza en la eficacia policial y el incumplimiento de sus funciones, ocasionaron que entre las primeras medidas dictadas por Miguel Tacón (1834-1838) al tomar el mando de la isla Miguel Tacón, estuviera la introducción de reformas en la vigilancia y control de la delincuencia. Su obra gubernativa -combinación de una férrea política represiva y una amplia labor constructiva en el entorno urbano-, se caracterizó, entre otras cuestiones, por numerosas disposiciones encaminadas a reprimir la vagancia y el juego, así como limitar la posibilidad de portar armas incrementando el número de las prohibidas. Probablemente es Tacón uno de las gobernadores generales de Cuba de la primera mitad del siglo XIX, sobre quien más se ha problematizado en cuanto a desempeño y alcance de sus métodos de gobierno.

La primera novedad de mando en la isla aparece con la creación de un Cuerpo de serenos, si para algunos la aparición en Europa de la policía estuvo determinada por la incapacidad de los vigilantes y serenos de lidiar con la delincuencia y el desorden, ${ }^{21}$ en Cuba el proceso es inverso, la aparición de dicho cuerpo responderá a la necesidad de crear una institución o fuerza auxiliar que apoyara a la policía en el mantenimiento del or-

\footnotetext{
${ }_{19}$ Actas del Ayuntamiento de La Habana 9 de abril de 1829. AOHH, Tomo 114.

20 Por regla general cuando en los debates se planteaban cuestiones de envergadura se creaban comisiones para realizar el estudio, una vez concluido el estudio se analizaban los resultados y las medidas sugeridas, que en caso de ser aprobadas por mayoría en el Ayuntamiento se elevaban al Gobernador para ser sancionadas por él.
} 
den, quedando su mantenimiento a costa de la corporación municipal. Paralelamente también introdujo modificaciones dentro de la organización de la policía, entre los que resalta su reestructuración y la definición de sus funciones a partir de la delimitación en policía urbana o rural.

En cuanto a la estructura, los 16 barrios de intramuros se redistribuyeron en cuatro cuarteles de policía, ${ }^{22}$ que coincidían con las cuatro brigadas de serenos constituidas, la dirección de los cuarteles quedó asignada a los cuatro alcaldes ordinarios existentes en ese momento, auxiliados para su desempeño de los tenientes de gobierno; de esa forma los comisarios que con anterioridad estaban entre los principales funcionarios pasaban ahora a tener la función de auxiliares. En los barrios de extramuros se crearon tres cuarteles bajo las denominaciones de Jesús María, Guadalupe y San Lázaro, al frente de los cuales fueron nombrados Inspectores Principales de Policía con iguales atribuciones que los alcaldes ordinarios y tenientes de gobernadores. En la pirámide de esa estructura se ubicaba el gobernador general.

Sin embargo, hechos delictivos como el robo, el hurto, los asaltos, etc., no disminuían, La Habana mantuvo su reputación de violenta, los mecanismos de vigilancia y represión establecidos para acabar con esos hechos permitían condenar a los acusados de cometerlos, pero no conseguían evitar que sucedieran. Los documentos judiciales, aunque contienen versiones contradictorias de los sucesos, recuperan la voz de los sujetos participantes, usualmente ignorada o silenciada en los relatos históricos, en muchos casos las prácticas delictivas mencionadas estaban asociadas a dificultades económicas motivadas por la falta de un empleo estable o una remuneración insuficiente para cubrir las necesidades diarias de los sujetos infractores, lo que inferimos a partir de los principales objetos robados: ropa, utensilios y objetos domésticos, utensilios de trabajo, dinero, etc.

Para el gobernador general Tacón el entorno delictivo era propiciado por la falta de efectividad en la actuación del cuerpo de policía, resultado de diversas situaciones. Una de ellas el deficiente alumbrado, más escaso aun en la zona de extramuros; así mismo consideraba como dificultad para una efectiva vigilancia y control la falta de actualización 
en los padrones, por lo que el esquema de control de la población impuesto por él se amplió hasta el nivel de barrio, los alcaldes fueron instruidos para que confeccionaran padrones que reflejaran el oficio u ocupación que desarrollaban los vecinos de su demarcación y sobre todo si la ejercían; donde hubiera talleres resultó obligatorio incluir una lista elaborada por los maestros, detallando el número de aprendices y operarios, así como la actitud que estos mostraban hacia el trabajo. Si bien en 1827 se elaboró un censo que reunía esas características, la condición de La Habana como centro administrativo y capital de la Isla, ocasionaba un constante movimiento poblacional en torno y dentro de la urbe, con un incesante crecimiento en sus habitantes.

Para controlar el cumplimiento de las disposiciones dictadas Tacón estipuló que los alcaldes y tenientes de gobierno despacharan directamente con él sobre lo acontecido en sus respectivos cuarteles, el procedimiento se complementaba con la amplia potestad conferida a los alcaldes para remover de sus cargos a comisarios y tenientes de gobierno sino cumplían sus obligaciones. En otro orden de cosas, mantuvo -y en algunos casos profundizó- las regulaciones dictadas por Manuel Cajigal y de la Vega (1819-1821) y Francisco Dionisio Vives en cuanto a vagos, mendigos, juegos prohibidos e ilícitos, exigencia de licencias para viajar, etc., poniendo trabas y limitando el libre movimiento de los habitantes por la urbe.$^{23}$

Sin embargo, a nuestro juicio, fue el factor económico el elemento que mayor incidencia tuvo en el deficiente desempeño de la policía. Los arbitrios del Ayuntamiento destinados a cubrir las necesidades de mantenimiento de la policía resultaban insuficientes, procedían básicamente, de ingresos percibidos por cobro de pasaportes, licencias y desembarque de pasajeros, así como la recaudación de las multas, alrededor de las cuales hubo muchas irregularidades

Para algunos funcionarios la solución al problema se resolvía pagando un salario a los integrantes del cuerpo policial, lo cual debía ser una motivación para perseguir a delincuentes y malhechores, así mismo evitaría que se vieran envueltos en sucios negocios o sobornados por comerciantes corruptos, o armando patrañas y calumnias para obtener beneficios económicos, una situación frecuentemente expuesta en las sesiones del Ayunla denominación de Santa Teresa. ANC. Fondo GSC. Leg. 1448, Exp. 56816.

${ }^{23}$ Como parte de su acción dictó nuevos bandos para controlar la portación de armas, incorporando nuevas en el acápite de las prohibidas, así mismo incrementó las acciones contra la vagancia, el juego y otras prácticas que atentaban contra el orden establecido, como colofón de ello creó un Tribunal de Vagos y Picaplei- 
tamiento y expresada por el procurador Salvador García Carrasco en los siguientes términos:

\begin{abstract}
Esto es lo que hace la policía; ocuparse de los chismes y en desacreditar a las personas [...] si entramos en los pueblos ¿Qué sucede?, que hay empleados de policía de poco sueldo que hacen la capa á los malvados, porque le gratifican. Es indispensable para que pueda esa institución servir a su objeto, que proteja la tranquilidad de los pueblos y vele sobre los delitos. ${ }^{24}$
\end{abstract}

La falta de integridad de algunos funcionarios del cuerpo los llevaba incluso a atribuirse derechos y prerrogativas que no les competían pero les proporcionaban beneficios personales, las ganancias eran mayores en la medida que superior era el cargo:

Los Comisarios de los Barrios en que se hallan situados los Mercados acudían a ellos con grandes canastas que llevaban á sus casas repletos de carnes, aves, frutas, verduras, que no les habían costado otra cosa que el exigirlo de los infelices vendedores, los cuales no osaban negarse a las exigencias del Comisario, porque sabían a no poderlo dudar que si lo hubiesen hecho habrían sido luego víctimas de su rencor y se habrían visto obligados á pagar continuas multas que los habrían arruinado, mientras que su silencio y su condescendencia les daban la seguridad de poder infringir impunemente los reglamentos del Mercado. ${ }^{25}$

La insuficiencia monetaria además de servir de pretexto y motivo para que la policía se viera envuelta en situaciones como las descritas, también originó que prestara mayor atención a aquellas obligaciones o responsabilidades que le proporcionaban entradas, como eran la emisión de documentos legales, la tramitación de la documentación a quienes querían contratarse y radicarse en la isla, así como atender a la búsqueda de personas desaparecidas, ${ }^{26}$ en tanto el mantenimiento del orden quedaba relegado a un segundo plano.

Un informe remitido por Juan Nepomuceno a Miguel Tacón, con fecha $1^{\circ}$ de junio de 1835, resumía la situación de la siguiente forma:

Es sabido Sr. Excmo., que las funciones de esos empleados subalternos son casi gratuitas, porque los cortos emulentos que perciben y cobran por ciertas diligencias gracias de su atribución, no alcanzan a cubrir las precisas necesidades de un padre de familia, que dedicado al servicio publico no puede proporcionar por medio de una industria o profesión. De ahí es que el bodeguero, el tendero, el alma-

tos en el cual ejercía como máxima autoridad. MARTíNEZ, Yolanda Díaz. Visión de la otra Habana: delito, poder y control social. Santiago de Cuba: Oriente, 2012.

24 Actas del Ayuntamiento de La Habana. 23 de abril de 1835. AOHH, Tomo 127.

25 "Reseña del Estado e inconvenientes de la policía que se hallaba establecida en La Habana hasta mayo de 1851" 22 de mayo de 1852. ANC, Fondo GSC, Leg. 1332, Exp. 52065.

${ }^{26}$ Las denuncias de personas desaparecidas fue uno de los aspectos a los que se le prestó especial atención a causa de las elevadas tarifas cobradas por este servicio, que rebasó las fronteras nacionales como lo evidencia el caso de María Encarnación Sánchez, española, que solicitaba la localización de su esposo Juan Benigno Gómez que había partido hacia Cuba con la intención de encontrar mejores condiciones de trabajo y ayudar al mantenimiento de ella y su hijo y sin embargo se había desentendido de ellos; así supo Encarnación que su esposo se había radicado en la zona de Río Blanco y usando la mentira había formado una nueva familia. Al respecto ver "Solicitud realizada por María Encarnación Sánchez para que se localice a su esposo Juan Benigno Gómez ausente del hogar" ANC. Fondo GSC, Leg. 1331, Exp. 52001. 
cenista, y otros que menudean sus efectos suelen ser contribuyentes de los comisarios y de los policías, quienes a su vez compensan la forzada generosidad de estos vecinos con una convivencia perjudicial; porque al fin que todo es vivir y puesto el hombre en conflicto entre su deber y la necesidad de subsistir, no es extraño que prefiera ésta a aquel. Sería pues muy conducente que a esos empleados se les diese una asignación fija, que unida a sus emulentos, les proporcionase una decente subsistencia y los constituyese en una independencia de aquellos a quienes debe celar. Entonces pudiera el Gobierno exigirles una severa responsabilidad por la más pequeña falta que ellos procurasen evitar y no hicieren [...]. ${ }^{27}$

La incapacidad de la policía para controlar el ambiente delictivo de la ciudad y la multiplicidad de intereses que se movían a su alrededor, contribuirían a determinar su condición. A medio camino entre la modernidad que suponían los conceptos de la ilustración, con una institución que se dedicaba no solo a vigilar sospechosos y delincuentes sino también a organizar el funcionamiento adecuado de la sociedad y, de otra parte, limitada a los designios y disposiciones de la administración colonial dispuesta a perpetuar por todas las vías su control en la Isla, el debate se centraba en dos posibilidades o variantes para la policía: ¿política o judicial?

La estructura dada por Tacón a la vigilancia, en la cual se erigía como figura principal, le permitía tener un mejor control y disponer de funcionarios policiales que le rindieran total obediencia. Para los integrantes del Ayuntamiento no dejaba de ser una preocupación una policía con un marcado carácter político ¿podría perjudicar en algún momento a los miembros de la corporación municipal inconformes con las disposiciones del Gobernador General?, ¿podría esa policía tramar, como al parecer a veces hacía, alguna ardid para implicarlos? Asumimos que fueron algunas de esas inquietudes las que motivaron el interés del Ayuntamiento de proporcionarle un mayor carácter civil, sacándola, en la medida que sus posibilidades se lo permitía, de la égida del Capitán General; para conseguirlo resultaba esencial proporcionarle más fondos para que asumiese un mayor carácter judicial y quedase en mano de los funcionarios civiles y judiciales. Sin embargo, esto no pudo ser solucionado de manera inmediata por falta de presupuestos.

Cuando Gerónimo Valdés (1841-1843) asumió el mando de la Isla, encontró una policía que muy poco había avanzado en su honradez, como tampoco en la reducción de funciones y obligaciones, fiel reflejo de lo que acontecía en la Metrópoli:

En algunas provincias mientras malhechores conocidos salían á los caminos con pasaportes en regla, se exigían formalidades odiosas para darlos á vecinos honrados que exhibían sus cartas de seguridad; aquí un jefe de policía obligaba á los viajeros á comparecer en persona a sus oficinas ante un oscuro dependiente, mientras el delincuente y el ladrón se distraen impunemente, exigiéndoles multitud

27 Informe enviado por Juan Nepomuceno a Miguel Tacón. 1ำ de junio de 1835, ANC, Fondo GSC, Leg. 1334, Exp. 52103. 
de requisitos inútiles cuando menos, y casi siempre contrario a los reglamentos $[\ldots] .{ }^{28}$

En la Península se intentó solucionar la situación organizando el servicio policial a partir de observar extrema severidad con la persecución del crimen, cierta indulgencia con el descuido o flaqueza de la gente honesta, el respeto a la inocencia, la atención a todo aquel que reclamare su servicio, etc.; paralelamente se exigía evitar la deshonra por cualquier apariencia de arbitrariedad y, mucho menos, vejación en el ejercicio del servicio.

En Cuba la situación se volvía más compleja a causa de la falta de presupuestos para pagar un salario fijo a los integrantes del cuerpo, el exceso de atribuciones por parte de algunos de sus integrantes, conceder prioridad a las cuestiones políticas por encima de las judiciales, así como la existencia de comportamientos fuertemente enraizados dentro de la población como el juego, la vagancia, el consumo de alcohol, etc. Para intentar dar solución a algunas de estas deficiencias y que también en la isla prevalecieran los mismos principios establecidos en la Península, dirigió Gerónimo Valdés parte de su actividad gubernativa.

En correspondencia con esa intención, el 22 de abril de 1842 emitía una circular aclarando las obligaciones que compelían a la policía en la persecución de los delincuentes, y afirmaba "[...] A la policía toca curar esta llaga vergonzosa y funesta, y lo logrará en breve sin duda con el empleo simultáneo de todos los medios que a ello conducen". ${ }^{29}$ Valdés clasificaba esos medios en preventivos y represivos. Reflejo de la actividad controladora encaminada a conocer y ubicar a cada habitante, dentro de los medios preventivos se incluía: conocer la situación de cada pueblo y las personas que los habitaban, el sustento con que contaban, la forma en que empleaban su tiempo, los sitios de juego y ocio más concurridos, etc., así mismo exigía que los maestros y dueños de talleres tuviesen sus registros actualizados, en tanto era obligación de los alcaldes tener actualizados los padrones vecinales.

En cuanto a los represivos sus indicaciones eran precisas:

[...] poner en movimiento, apenas se anuncie un robo o la ejecución de cualquier delito, la fuerza necesaria, sea incluso de tropa, para reconocer los sitios aledaños, de ser necesario las moradas que puedan servir de escondites, y seguir el

\footnotetext{
28 Preámbulo introductorio al acápite de Causa de policía. In ZAMORA, José María. Biblioteca de Legislación Ultramarina en forma de Diccionario Alfabético. Madrid: Imprenta de J. Martín Alegría, 1849, Tomo 5. p. 92-95.

29 "Circular para el eficiente cumplimiento de las funciones de la policía". 21 de enero de 1842. ANC, Fondo GSC, Leg. 1331, Exp. 52035.
} 


\section{Passagens. Revista Internacional de História Política e Cultura Jurídica \\ Rio de Janeiro: vol. 9, no. 3, setembro-dezembro, 2017, p. 391-415.}

rastro del malhechor ó malhechores hasta entregarlos en las manos de la justicia. ${ }^{30}$

En ese propósito involucraba a la población de la cual exigía colaboración, so pena de ser llevada ante la justicia toda persona que se negase a hacerlo. Pero la gestión de Gerónimo Valdés -sobre la base de la misma estructura y división de cuarteles por barrios ya existente-, tampoco consiguió resolver muchos de los problemas que afectaban a la sociedad, tal y como exponía en una carta remitida a una autoridad en la Península:

[...] no es posible, una vez continuados durante tantos años, acabar con la plaga de vagos y ociosos que pueblan esta ciudad, en medio del desconcierto y el pillaje de quienes encuentran mas fácil vivir de la caridad, el juego o la incitación judicial, provocando dilatados juicios, que emplearse en aras de traer la prosperidad y beneficio al país. Hoy no es posible acabar con esos graves problemas, ni los medios existentes para hacerlo lo permiten y ello significaría remover las costumbres de un pueblo adaptado a vivir de manera fácil. ${ }^{31}$

Una de las demandas que enfrentó Gerónimo Valdés en su Juicio de Residencia fue la imposibilidad de garantizar para la ciudad la tranquilidad que todos reclamaban y que nadie conseguía.

\section{Nueva reforma policial}

En los años subsiguientes no se aprecian cambios significativos ni en cuanto a estructura del cuerpo de policía, ni de reformas para el mejor desarrollo de su actividad. La crítica a su actuación se mantuvo con un permanente cuestionamiento a la eficacia de los integrantes del cuerpo, enunciado abiertamente en un informe presentado al gobernador general de la isla por la Junta Consultiva de Gobernación y Policía, constituida en La Habana en el año 185, con el propósito de estudiar las reformas que hicieran más eficiente el servicio del cuerpo judicial, el documento expresaba la imposibilidad de que la justicia pudiera marchar de manera adecuada, entre otras causas: "[...] por una policía con agentes que por toda recompensa queden casi obligados a convertir en torpe y mezquina gangrería los deberes de su delicado y comprometido empleo."32 Y ampliaba:

Los agentes de policía en la Isla viven sin sueldo fijo y se hallan casi precisados o a valerse de vejaminosas exacciones que molestan al vecino y exacerban su ánimo o a ser remisos en el cumplimiento de su obligación para tener una utilidad que su celo no les proporcionaría. Triste es el cuadro que la Junta se atreve tener la

30 "Circular para el eficiente cumplimiento de las funciones de la policía". 21 de enero de 1842. ANC, Fondo GSC, Leg. 1331, Exp. 52035.

31 "Carta de Gerónimo Valdés a J. Machado". 24 de abril de 1843. ANC. Fondo GSC, Leg. 1332, Exp. 52070 .

32 Informe Consultivo de Gobernación y policía de La Habana. 23 de enero de 1851. ANC, Fondo GSC. Leg. 1406, № 55050. 
honra de exponer, pero más lamentable son su perniciosa realidad y los resultados que de aquí nacen [...] Muchos establecimientos se hallan sufriendo una especie de cotización a consecuencia de lo que va indicado, y de ellas solo males y desmoralización es lo que puede esperar. Si pues existen agentes que apliquen sin desvirtuar las disposiciones que constituyan el bando de gobernación y policía, fuerza es que se hallen dotados convenientemente para que apliquen los conceptos de aquel y vigilen su observancia, sin necesidad de las contemplaciones que deben ahora guardar y son causa de la impunidad de los infractores. ${ }^{33}$

En similares términos se expresaban algunos integrantes del Ayuntamiento de la Habana en un informe emitido al Gobernador general: "[...] porque servicios constantes, activos, eficientes y necesarios a las normas de conducta, no pueden exigirse que sean cumplidos sin otra retribución que emulentos eventuales y escasos en los que nadie puede fundar su subsistencia". ${ }^{34}$

La policía se había "apropiado" de diversas estrategias para disponer de un financiamiento que ni la administración colonial, ni el Ayuntamiento eran capaces de asegurarle, entre las más frecuentes estuvieron el cobro por encima de lo fijado en las tarifas por servicios que eran de su competencia, la exigencia de pagos a dueños de negocios argumentando violación en lo establecido, hasta fijar arbitrios indebidos para beneficio propio como la denominada iguala, mediante la cual los dueños de establecimientos pagaban a los agentes entre uno y cuatro pesos mensuales para verse libres de la vigilancia policial y con derecho de faltar a todas, o casi todas, las prescripciones fijadas en los bandos dictados por el gobierno.

Parte de la obra gobernativa de José Gutiérrez de la Concha en su primera etapa (1850-1852), estuvo encaminada a resolver la problemática existente en torno a la policía, para conseguirlo realizó la reforma del cuerpo policial y creó la Comisión Superior de Policía como base de sus aspiraciones moralizadoras. En ese contexto nuevamente cobró fuerza la polémica sobre el sostenimiento económico de los funcionarios y agentes policiales y -a tono con ello-, la cuestión de la subordinación del Cuerpo, una de las tantas formas en que se expresaron las contradicciones entre la administración colonial y la corporación municipal.

El gobernador general consideraba al Ayuntamiento como principal responsable del pago de los gastos de policía teniendo en cuenta que la función y actividad del cuerpo era en beneficio de la ciudad. El Ayuntamiento, por su parte, no disponía de recursos si no creaba nuevos arbitrios para ingresar a los fondos de propios pues con los existentes no

\footnotetext{
${ }^{33}$ Informe Consultivo de Gobernación y policía de La Habana. 23 de enero de 1851. ANC, Fondo GSC. Leg.
} 1406, № 55050. 
era posible ${ }^{35}$ pero tampoco podía crearlos atendiendo a la Real Orden de 16 de abril de 1850 que prohibía la imposición de nuevos arbitrios sin autorización del Rey. Por otra parte, tampoco se aprobaba hacer pesar sobre las cajas reales ningún gasto nuevo.

No dejaba de preocupar a la administración colonial algunos acontecimientos que se habían presentado en la isla, entre ellos el desembarco de Narciso López en mayo de 1850 y el aliento que esto proporcionaba a las ideas anexionistas, en tal sentido consideraba el gobernador general Gutiérrez de la Concha:

El instinto natural de conversación hacía comprender de tal modo en aquellos momentos a todos los buenos españoles la necesidad urgente de organizar la policía y de crear una fuerza para garantizar el orden público, que nunca hubiera sido menos sensible la imposición de cualquier arbitrio destinado a semejante objeto. ${ }^{36}$

El apremio en resolver la situación de las reformas en la policía y el hecho de carecer de suficientes fondos determinó la decisión de que la Real Hacienda anticipase todos los gastos del cuerpo de policía y salvaguardias, con la condición de que los ayuntamientos posteriormente devolverían la parte que les correspondiese. En los años próximos los gastos para el mantenimiento del cuerpo se dividieron en gastos del estado y del Ayuntamiento, no sin que frecuentemente las corporaciones municipales de los territorios en que se aplicó la reforma (La Habana, Matanzas, Puerto Príncipe y Santiago de Cuba) se vieran apremiados para poder sufragarlos.

La situación de las finanzas y presupuestos sirvió así de pretexto para hacer desaparecer algunas estructuras cuando estas no convenían a los intereses de la administración colonial, como fue en 1854 la supresión del Cuerpo de Salvaguardias rurales encargado del patrullaje y vigilancia en las zonas de extramuros y las rurales. La creación del cuerpo de Salvaguardias en el año 1851, integrado a la policía respondió, según el gobernador general, a la necesidad de "[...] acabar con la falsa moralidad del sistema de jueces

\footnotetext{
34 Oficio remitido al Gobernador General por la Secretaría Política del Ayuntamiento de La Habana. 3 de abril de 1851. ANC, Fondo GSC, Leg. 1461, exp. 57851.

35 Los fondos de propios de La Habana se conformaban fundamentalmente de tres entradas: una sobre carruajes, conocida con el nombre de marca, era la más sustanciosa y se dedicaba a la recomposición de calles y algunas obras públicas indispensables, el otro era lo pagado por las contratas de los mercados y rastros, de muy bajos ingresos por ser muy poco lo que se pagaba por ellas y finalmente estaba la que se obtenía del $4 \%$ pagado por las ventas de casas. En ese momento se evaluaba la imposición de un nuevo arbitrio sobre la industria y el comercio, entendiendo que existían empresas que llegaban a tener utilidades por encima del $18 \%$ y no satisfacían dividendos para el Estado o los fondos municipales. "Consideraciones al Ministro de Gobernación sobre posibles financiamientos de la policía" 2 de julio de 1851. ANC, Fondo GSC, Leg. 1461, exp. 57851.

${ }^{36}$ GUTIÉRREZ DE LA CONCHA, Jos. Memorias del Estado político, gobierno y administración de la isla de Cuba. Madrid: Establecimiento Tipográfico de José Trujillo, 1853, p. 176.
} 
pedáneos, ${ }^{37}$ que repugna tanto a los paisanos del país a causa del abuso que cometen." ${ }^{38}$ El Ayuntamiento se negó a sufragar sus gastos argumentando que eran excesivos y el Ayuntamiento de La Habana no podía sufragarlos, además de no ser un servicio de beneficio para la ciudad, por lo que fueron asumidos en su financiamiento fue asumido por el gobierno colonial.

Sin embargo, por un decreto de 1854, cuando ya el peligro anexionista había pasado y el desembarco de nuevas expediciones quedaba descartado, el gobierno propuso sustituir los salvaguardias por un batallón de la Guardia Civil perteneciente al ejército permanente destacado en la isla y financiado desde la Península, las ventajas de esa decisión quedan reflejadas en el siguiente fragmento:

Estimular la permanencia en el país de los soldados cumplidos a fin de hacer menores los sacrificios que impone a la Nación y al Erario su costoso reemplazo. Dicha fuerza al formar parte del ejército aliviará al estado de una gran carga y los Ayuntamientos de lo poco que abonaban por el costo de los salvaguardias y cargarles a aquellos el de los comisaros y celadores que hoy paga la Hacienda [...]. ${ }^{39}$

Una nueva estructura para la policía fue aprobada por la Reina en el año 1855. Con ella se intentaba, por una parte, buscar mejores resultados en el funcionamiento del cuerpo y cortar las continuas críticas a sus integrantes, pero también era evidente su intención de cortar de una vez y por todas los constantes desacuerdos con el Ayuntamiento al subordinar el cuerpo de manera absoluta al gobierno central de la colonia. ${ }^{40}$ Por disposición real los integrantes recibirían un sueldo fijo, aclarando que esto garantizaría que no tuvieran que buscar entradas o recompensas por otras vías. La decisión de nombrar como jefe Superior de Policía Urbana al jefe del cuerpo en La Habana, subordinado directamente al Capitán General, expresa la intención de la administración colonial de supeditar y disponer de este órgano en función de sus necesidades e intereses.

En la nueva estructura se restauraba el Cuerpo de Salvaguardias y se mantenía a la Guardia Civil, con funciones muy bien delimitadas: los primeros quedaban encargados de velar por el mantenimiento del orden y la tranquilidad pública en las zonas rurales, mientras que para los segundos la misión fundamental estaba enfocada a contrarrestar cualquier acción política que pudiera desestabilizar la vida de la colonia, en la práctica

\footnotetext{
${ }^{37}$ La figura del juez pedáneo en la zona de extramuros y los poblados rurales era el equivalente de los alcaldes ordinarios en la ciudad, al igual que estos asumían funciones tanto administrativas como judiciales.

${ }^{38}$ Expediente sobre el establecimiento de la Policía en La Habana." 7 de septiembre de 1851. ANC, Fondo GSC, Leg. 1461, exp. 57851.

39 Expediente sobre el establecimiento de la Policía en La Habana." 7 de septiembre de 1851. ANC, Fondo GSC, Leg. 1461, exp. 57851.

40 "Real Orden sobre la organización del Cuerpo de policía de la Isla." Mayo de 1855 ANC, Fondo Colección de Reales Decretos y Órdenes (en lo adelante CRDO), Leg. 185, exp. 45.
} 
ambas fuerzas se entrecruzaron en más de una ocasión en el cumplimiento de sus obligaciones.

Pero poco podía conseguirse en el mejoramiento de la actividad policial con un cambio de estructuras, si quienes la ejercían carecían de moralidad para ejercer sus funciones. Las dificultades iban más allá de imponer multas excesivas en mercados y plazas o exigir pagos por encima de lo fijado en los servicios de los cuales era responsable la policía, las quejas también se referían a los celadores, en el período comprendido entre julio de 1855 y septiembre de 1856 fueron separados de sus cargos un total de 45 de esos funcionarios por disímiles causales, siendo las más frecuentes: llevarse alimentos de los establecimientos sin pagarlos, aceptar sobornos por permitir juegos prohibidos, no actuar a tono con sus responsabilidades o llevar una vida personal cuestionable al convivir en amancebamiento o aceptando los favores de meretrices para que estas pudieran ejercer su oficio.

En algunos casos el inadecuado desempeño de los celadores rebasó la simple separación del cargo y fueron llevados a la cárcel como aconteció en noviembre de 1855 con Francisco Cerezo, celador del barrio de San Lázaro que fue conducido a prisión por las sucesivas quejas que sobre él existían, la investigación iniciada por el Jefe Superior de Policía demostró la veracidad de muchas de las imputaciones: amenazas contra quienes podían denunciarlo o quienes no se sometieran a sus exigencias, uso de la fuerza, reclamo de dinero a personas pretextando que cometían violaciones, desvirtuar desarrollo de hechos para obtener beneficio económico de los implicados y falta de moral en su comportamiento como persona: "Intentando despertar la sensualidad en una niña de once años, lisonjeándose que sería él quien se llevaría su virginidad y que luego de llevar aparentemente una vida ordenada en su hogar, vivía amancebado con una yucateca y una negra." 41

Las dificultades en torno a la capacidad y moralidad de los funcionarios policiales para desempeñar sus cargos fue una situación que se mantuvo a lo largo de la centuria, si tomamos en cuenta la información que ofrecen las fuentes documentales continuamente eran removidos de sus cargos inspectores, sub-inspectores y celadores bajo el criterio de no reunir las condiciones adecuadas para el desempeño. Ni siquiera la circular de diciembre de 1860 que disponía era el Gobierno Superior de la Isla quien los aprobaba, previa presentación de sus antecedentes y cualidades conseguía que fuera una garantía. 
Para algunos la solución podía estar en crear una policía secreta, básica para garantizar una mayor eficiencia y transparencia en los integrantes del cuerpo ordinario. Pero cualquier reforma tenía el inconveniente de la parte económica, con los consiguientes gastos para el presupuesto municipal que no tenía como enfrentarlos y las cajas de una Real Hacienda que igualmente se resentía de sus fondos. Por esa razón, más que nombrar nuevos funcionarios o realizar cambios en las estructuras creadas lo que se hizo fue reordenar la distribución de los efectivos en nueve distritos donde quedaran incluidos todos los barrios de la ciudad y redistribuir las capitanías de partida en cinco a fin de facilitar de manera más organizada el patrullaje de las salvaguardas montados. ${ }^{42}$

Las evidencias documentales apuntan que no fue hasta la década de 1880 en que se acometieron nuevos cambios significativos en el cuerpo policial, apremiados por las consecuencias de una guerra que había sacudido la parte centro oriental de la isla entre los años 1868 y 1878 y que, aunque no llegó al extremo occidental y en particular a la capital, trajo como consecuencias movimientos de personas hacia esa región en busca de mejores oportunidades, condicionando el establecimiento de nuevas estructuras para vigilar y controlar el delito.

El nuevo reglamento orgánico aprobado el 10 de mayo de 1883, en una coyuntura de agitación política en la isla, confería el cargo de Jefe superior de policía al Gobernador General, quien continuaba designando a nivel de provincia los cargos más importantes en orden jerárquico desde alcalde hasta celador, siempre a propuesta de los gobernadores provinciales. A partir de ese momento la actividad del cuerpo se centró en la prevención y persecución de los delitos comunes, encargando a la Guardia Civil del mantenimiento del orden vinculado a los hechos de carácter político.

La última reorganización de la actividad policial acaeció en 1993 por Decreto Real. La novedad de su proyección radicó en la creación del Cuerpo de Orden Público, con independencia del Cuerpo de Policía; a partir de ese momento la actividad policial pasaba a ser sufragada de manera íntegra por las arcas del Ayuntamiento, en tanto el nuevo organismo creado dependería del Ministerio de la Guerra en su organización y régimen disciplinario, en cuanto a servicio quedaba subordinado al Gobernador General, quien asumía funciones de Inspector y podía disponer de él en caso de guerra o alteración del orden

\footnotetext{
41"Expediente del personal de policía de La Habana”. 11 de noviembre de 1855, ANC, Fondo GSC, Leg. 1464, exp. 57907.

42 "Expediente promovido para ordenan el personal de Policía de La Habana". 23 de octubre de 1878. ANC, Fondo Gobierno General (en lo adelante GG), Leg. 286, exp. 13965.
} 
público. ${ }^{43}$ Esa estructura permanecería hasta ocupar militarmente Estados Unidos la isla en 1899.

\section{Conclusiones}

A modo de cierre, valdría recalcar tres ideas esenciales. La primera de ellas tiene que ver con el tipo de policía que encontramos en La Habana, a todas luces de carácter urbano, cuya administración y subvención corresponde al poder local, en este caso representado por el Ayuntamiento de La Habana, pero cuyos márgenes con el poder central del estado, vale aclarar la administración colonial encabezada por la figura del gobernador general, se vuelven difusos y en ocasiones motivo de contradicción entre esas dos fuerzas por ejercer el control sobre la policía, propiciado no solo por una cuestión de relevancia política, sino por la capacidad monetaria para enfrentar los gastos del cuerpo.

Le segunda está asociada a las frecuentes quejas que daban cuenta de la ineficiencia mostrada por el cuerpo de policía durante el siglo XIX, una situación que se intentó de solucionar a partir de la emisión de diversos reglamentos y decretos introduciendo modificaciones en su estructura y modo de ejercer la actividad, pero que no consiguieron ese propósito, manteniéndose a lo largo de la centuria sucesivos cuestionamientos acerca de su desempeño.

La tercera idea tiene que ver con las causas u origen de las deficiencias del cuerpo que podríamos agrupar en dos grupos: objetivas y ajenas al personal de policía y subjetivas y asociadas a las cualidades de sus integrantes. Dentro del primer grupo se enumeran el deficiente alumbrado, las extensas zonas a patrullar o la insuficiencia de personal; en cuanto a las segundas cabe resaltar la falta de preparación y aptitud de los integrantes en su mayoría voluntarios, la ausencia de una motivación al carecer de un salario fijo que permitiera disponer de una remuneración con que cubrir sus necesidades, lo que nos lleva a una última causa: la falta de moral y la deshonestidad de algunos de integrantes del cuerpo que en su empeño por conseguir dinero transaban en permitir violaciones a lo estipulado o se excedían en sus funciones.

\section{Referencias}

43 Periódico La Discusión, 18 de abril de 1893. ANC, Fondo AP, Leg 272, № 4. 
EMSLEY, Clive. Los modelos de policía en el siglo XIX. In: GALEANO, Diego; KAMINSKY, Gregorio (Org.). Mirada (de) uniforme: historia y crítica de la razón policial. Buenos Aires: Teseo, 2011. p. 21-46.

GALEANO, Diego. En nombre de la seguridad: lecturas sobre política y formación estatal. Cuestiones de Sociología, Buenos Aires, n. 4, p. 102-125, 2007. Disponible en: <http://www.cuestionessociologia.fahce.unlp.edu.ar/article/view/CSn04a05>. Acceso en: 4 abr. 2017.

GALEANO, Diego; KAMINSKY, Gregorio (Org.). Mirada (de) uniforme: historia y crítica de la razón policial. Buenos Aires: Teseo, 2011.

GAYOL, Sandra; KESSLER, Gabriel (Org.). Violencia, delitos y justicia en Argentina. Buenos Aires: Manantial SRL, 2002.

GUTIÉRREZ DE LA CONCHA, Jos. Memorias del Estado político, gobierno y administración de la isla de Cuba. Madrid: Establecimiento Tipográfico de José Trujillo, 1853.

HOLLOWAY, Thomas H. Policing Rio de Janeiro: repression and resistance in 19thcentury city. California: Stanford University Press, 1993.

KINGMAN GARCÉS, Eduardo; GOETSCHEL, Ana Maria. Seguridad y policía en la ciudad de Quito en el siglo XIX e inicios del XX. Revista Latinoamericana de Seguridad Ciudadana, Quito, n. 7, p. 74-82, mayo 2009. Cross ${ }^{\text {Ref. }}$

MARTÍNEZ, Yolanda Díaz. Visión de la otra Habana: delito, poder y control social. Santiago de Cuba: Oriente, 2012.

PALMA ALVARADO, Daniel (Org.). Delincuentes, policías y justicia: América Latina, siglos XIX-XX. Santiago: Ediciones Universidad Alberto Hurtado, 2016.

REGLAMENTO de policía. In: Colección Facticia de Vidal Morales. La Habana: Compilado por la Biblioteca Nacional de Cuba José Martí. T. 57. p. 20-25, 1820. Disponible en: $<$ http://www.bnjm.sld.cu/cgi-

bin/search.py?cadbusca="Col.+facticia"+"reglamento+de+policía"\&idficha=bnjmsculyfof00 10001\&idcatalogo=\&api_key=\&start=0\&rows $=10 \& \mathrm{i}=1 \& \mathrm{j}=1 \&$ sort=id+asc $>$. Acceso en: 12 abr. 2017.

REITH, Charles. The police idea, Oxford: Oxford University Press, 1938. 
ROCHE MONTEAGUDO, Rafael. La Policía y sus secretos en Cuba. La Habana: Imprenta La Moderna Poesía, 1925.

TRUJILLO Y MONAGAS, José. Los criminales de Cuba: narración de los servicios prestados en el Cuerpo de Policía de La Habana. Barcelona: Establecimiento Tipográfico de Fidel Giró, 1882.

VACCARONI, Agustina. La Intendencia de Policía de Buenos Aires: de las reformas a la Revolución, Gobierno, Higiene urbana y Control Político, Revista de la Red Intercátedras de Historia de América Latina Contemporánea, Córdoba, año 2, n. 3, p. 8-23, dic. 2015. Disponible en: <https://revistas.unc.edu.ar/index.php/RIHALC/article/view/13419/17255>. Acceso en: 22 abr. 2017.

VARELA ZEQUEIRA, Eduardo. La policía de La Habana. La Habana: Imprenta La Universal, 1894.

ZAMORA, José María. Biblioteca de Legislación Ultramarina en forma de Diccionario Alfabético. Madrid: Imprenta de J. Martín Alegría, 1849. Tomo 5.

\section{Fuentes Documentales:}

- Archivo Nacional de Cuba

- Fondo Colección de Reales Decretos y Órdenes

- Fondo Asuntos Políticos

- Fondo Gobierno Superior Civil

- Fondo Gobierno General

- Fondo Colección de Reales Decretos y Órdenes

- Archivo de la Oficina del Historiador de La Habana.

- Acta de las sesiones del Ayuntamiento de La Habana. 